\title{
Life cycle energy and carbon footprint analysis of large MW scale grid connected wind power systems in India
}

\author{
Jani Das, and Rangan Banerjee \\ Department of Energy Science and Engineering, Indian Institute of Technology Bombay, Mumbai, India
}

\begin{abstract}
The centralized grid is the main electrical supply to the country. About $80 \%$ of the installed generation capacity is fossil fuel fired power plants, though there is increase in share of renewable generation over the years. India has significant wind potential, and a major share in the renewable generation of the country. The energy and carbon footprint sustainability of wind power systems in Indian conditions is the focus of this research. This paper presents a study of large grid connected wind storage systems with reference to the cradle to grave primary energy requirements and carbon emissions in an Indian scenario.
\end{abstract}

\section{Introduction}

Renewable power is clean sources of energy. When energy is converted from different sources, whether depleting or non-depleting, to usable form, there are environmental impacts. Methods for analyzing sustainability in terms of energy and environmental factors and subsequent comparison between different options, can direct future energy plans and policies.

Wind energy capacity over the world is roughly doubling every three years, with a global installed capacity of 539 GW. India ranks fourth among the world nations with a capacity of $33 \mathrm{GW}$ as on December 2017[1]. Wind power constitute $55 \%$ of the total renewable power in the country [2]. But the energy and environmental impact of wind turbine systems has to be throughout its life time has to be accessed in Indian situations. Life cycle study analyses material and energy flows in the life time of a system, to ascertain the energy and environmental sustainability.

Several life cycle assessment studies of wind turbine systems have been done and published in literature. Some studies have been done by wind turbine producing companies [3-5] and in scientific articles [6-9].These studies mainly focus on energy pay back and environmental impact of large wind power systems at different locations on the globe.

This paper presents a research related to two large scale grid connected wind farms located at two different locations in India, with different turbine manufacturers. Life cycle energy and carbon footprint analysis has been done on the two systems. Energy and environmental sustainability of the systems have been compared by energy payback time, net energy ratio and emission factor.

\section{Life Cycle Analysis Methodology}

The life cycle assessment (LCA) used in the paper is consistent with the ISO standards [10-12]. A wind farm and its subsequent auxiliaries are analysed during all phases of its life cycle from cradle to grave, material production, manufacturing of its main components, transportation to the wind farm site, the installation, the startup ,maintenance and final dismantling and stripping down to waste materials which are either recycled, incinerated or landfilled. The end of life scenario of the system is considered as a separate stage. Material production refers to extraction of raw materials from earth or recyclates and refining them to usable materials which were used to manufacture the grid connected wind farm. Manufacturing represents all the processes required to convert the raw materials into wind farm components and assembling it into the final product. The cradle to grave primary energy requirements $\mathrm{E}$ in $\mathrm{MWh}_{\text {th }}$ is given by

$E_{c t g}=E_{m p}+E_{m n f}+E_{\text {Inst }}+E_{\text {oper }}+E_{\text {tran }}+E_{\text {eol }}$

and carbon emission $\mathrm{CE}$ in $\mathrm{kgCO}_{2}$ for wind farm is given by

$$
C E_{c t g}=C E_{m p}+C E_{m n f}+C E_{\text {Inst }}+C E_{\text {oper }}+C E_{\text {tran }}+
$$

ctg stands for cradle to grave; mnf for manufacturing; inst for onsite installation; oper for operation and maintenance; tran for transportation and eol for end of life.

\subsection{System boundary}

Within the limits of the boundary, are the components of the wind turbine, the transportation of the turbine components and the transmission cable to the farm site, the installation of the farm, the operation and maintenance and dismantling after the life time of the 
system. Outside the limits of the boundary, are the transformer substation and the national electricity network.

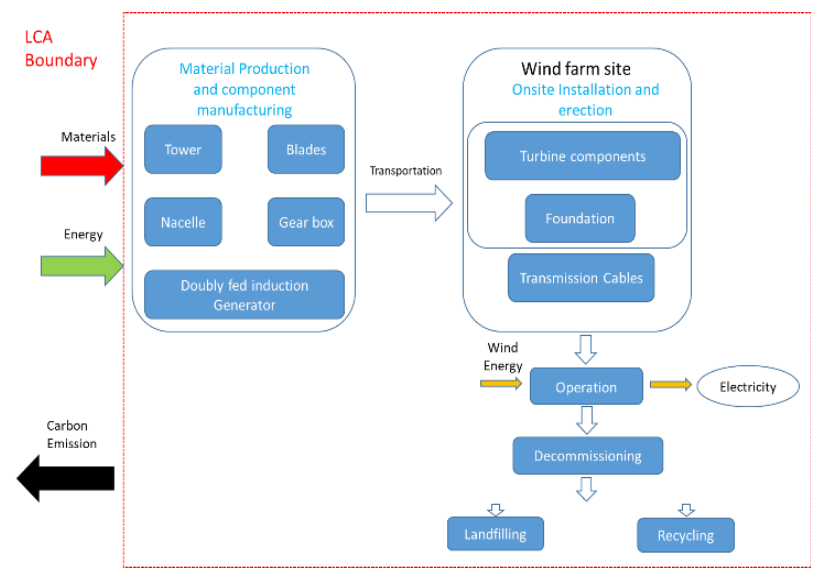

Fig. 1. LCA boundary of the system.

\section{Wind Generation System Under Study}

The wind farm considered for study consists of five onshore $2 \mathrm{MW}$ wind turbine systems of two different manufacturers (Vestas and Seimens), transmission system connecting the farm to the grid and the substation which connects the system to the electricity network. The specifications of the turbine systems are given in Table 1.

Table 1. Specifications of the wind turbines.

\begin{tabular}{|c|c|l|}
\hline Turbine Model & $\begin{array}{c}\text { Vestas } \\
\text { V90 }\end{array}$ & $\begin{array}{c}\text { Seimens } \\
\text { Gamesa G80 }\end{array}$ \\
\hline $\begin{array}{c}\text { Rated } \\
\text { Power(kW) }\end{array}$ & 2000 & 2000 \\
\hline Cut in wind speed(m/s) & 4 & 3.5 \\
\hline Rated wind speed(m/s) & 13 & 12 \\
\hline Cut out wind speed(m/s) & 25 & 25 \\
\hline $\begin{array}{c}\text { Generator } \\
\text { type }\end{array}$ & $\begin{array}{l}\text { 4-pole }(50 \mathrm{~Hz}) / 6 \text {-pole }(60 \mathrm{~Hz}) \\
\text { doubly fed generator, slip } \\
\text { rings }\end{array}$ \\
\hline
\end{tabular}

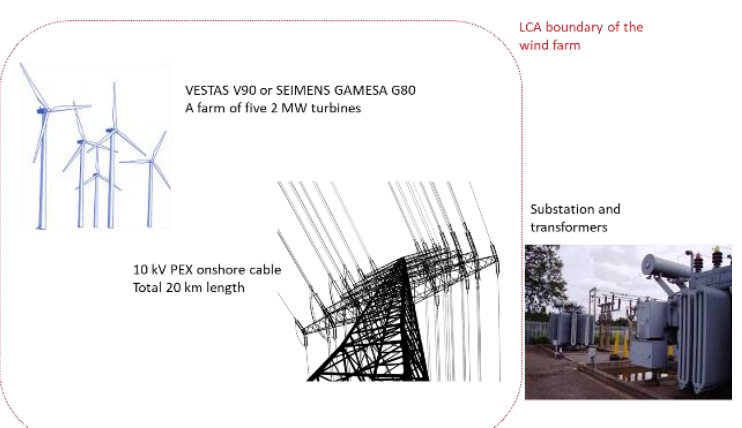

Fig. 2. Sketch of the wind farm.

The sketch of structure of wind farms considered is illustrated in Fig. 2. The wind farms are assumed to be located at Tuticorin, Tamil Nadu and Kutch, Gujarat.
The turbines considered for study are Vestas V90 and Seimens Gamesa G80. The various components of the wind turbine are manufactured at different parts of the world and transported to India for the wind farm installation. The manufacturing points of the two systems are illustrated in Fig. 3. The map helps to identify the magnitude of transportation energy on the overall energy impact of the system.

The first step in life cycle analysis is the preparation of the life cycle inventory. The wind turbine manufacturing materials are quantified as part of the preparation of the life cycle inventory. The materials which are used for manufacture can be directly from the ore or can be from recycled materials. The term "virgin" corresponds to materials which are taken directly from earth. The Virgin/Recycled ration gives the percentage of both types of materials in the overall structure. Manufacturing includes the material and energy input for assembling the different components into the final product or a part of it. The various components are transported to the site and the energy is quantified as transportation energy. Onsite installation also requires a significant amount of energy investment. The decommissioning phase of the wind energy system should also be considered with implications on the system and environment.

\subsubsection{Vestas V90 Turbine}

Vestas Wind systems is of Danish origin and have manufacturing points at various places in India. The turbine under study is a $2 \mathrm{MW}$ system with a doubly fed induction generator.

\subsubsection{Seimens GAMESA G80 Turbine}

Seimens Gamesa Renewable Energy is a Spanish wind turbine manufacturing company mainly located in Spain. A $2 \mathrm{MW}$ turbine with similar characteristics is used for comparison.

\section{Energy and Carbon Footprint Analysis of the Wind Generation System}

The components of life cycle energy are quantified for both the turbines situated at the locations considered for study. Two different scenarios are analyzed for the decommissioning phase of the system;

a) Scenario1-100\% landfilling of the system

b) Scenario2-Partial recycling and landfilling of the system

The energy sustainability is measured in terms of Energy Pay Back Time (EPBT) given by

$$
E P B T=\frac{E_{\text {ind }}}{E_{\text {out }}} \quad E P B T>0
$$

$E_{\text {ind }}$ is the total of indirect energy given to the system $\left(M \mathrm{Mh}_{\mathrm{th}}\right)$ and $\mathrm{E}_{\text {out }}$ is the annual electricity generated expressed in thermal units.

\subsection{The turbines}




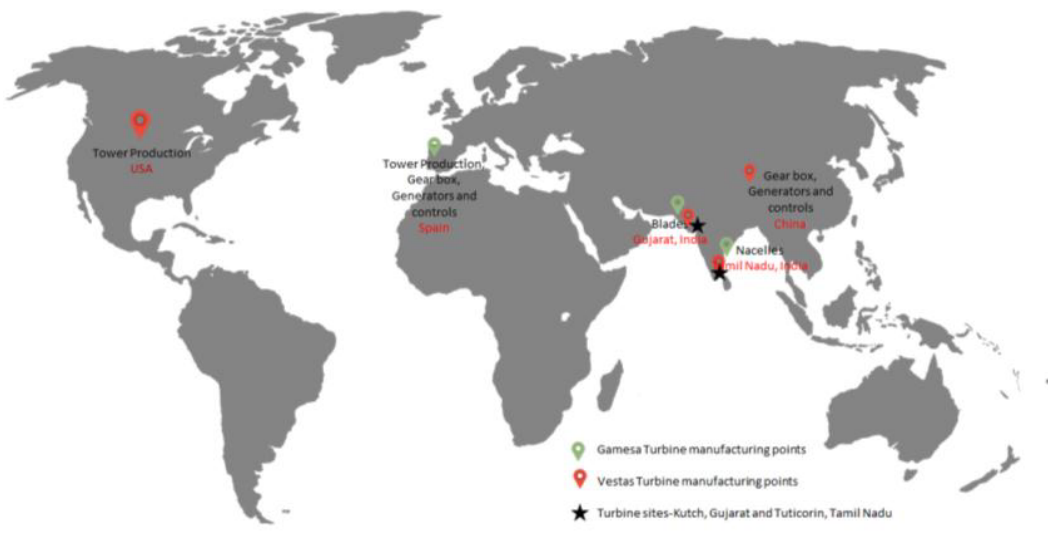

Fig. 3. Manufacturing points of the two turbine systems.

The transportation energy constants calculated for road transport is $341.5 \mathrm{~kJ} /$ ton-km and for sea transport is $120.3 \mathrm{~kJ} / \mathrm{ton}-\mathrm{km}$ for India. The corresponding carbon emission factors are $2.124 \times 10-4$ and $8.713 \mathrm{E} \times 10-6$ $\mathrm{kgCO}_{2} / \mathrm{kg}-\mathrm{km}$ respectively. The conversion factor for electricity to Primary Fossil energy is taken as 0.38, owing to the electricity generation mix of India dominated by thermal power, primarily coal [13]. The embodied carbon for electricity generation in India is taken as $0.94 \mathrm{kgCO} 2$ per unit [14]. The conversion factor for heat to Primary Fossil Energy is 1.

The carbon footprint of the wind farm is quantified as the emission factor (EF) expressed as carbon emission per unit generation of electricity scaled to a year.The wind farm life time is 20 years. Primary energy requirements and the emission factor of the two decommissioning scenarios for both locations are dealt with separately in the following sections.

\section{1. $100 \%$ landfilling of the system}

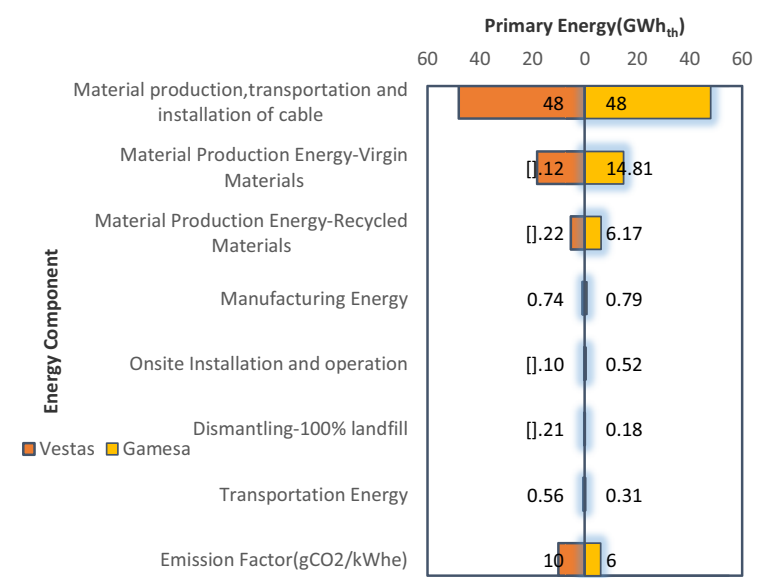

Fig. 4. Energy and emission comparison for Scenario 1 for Tuticorin.

The entire wind farm is landfilled including the foundation and the turbine components. None of the components are recycled. The values for Tuticorin are shown in Fig. 4. It is assumed that $1.1 \%$ of the total primary energy is used for landfilling of the system and the landfilling site is $5 \mathrm{~km}$ away from the farm site.

\subsection{Partial Recycling and landfilling of the system}

The alternate dismantling scenario considered for comparison is partial recycling of materials used for the production of the turbine and the transmission system. Tables 2 and 3 give the details of the material type and the disposal method considered for analysis for the two turbines. The metals are recycled, while the concrete used for manufacturing the foundation of the turbines are landfilled completed. Plastics, fiber glass and resin are incinerated. The primary energy requirements and the emission factor comparison is done.

Table 2. Disposal Scenario of V90.

\begin{tabular}{|c|c|}
\hline Material type & Disposal method \\
\hline Steel & Recycled $(90 \%)$ \\
\hline Copper & Recycled $(90 \%)$ \\
\hline Iron & Recycled $(90 \%)$ \\
\hline Aluminium & Recycled $(90 \%)$ \\
\hline Plastic & Incinerated $(100 \%)$ \\
\hline Concrete & Landfill $(100 \%)$ \\
\hline
\end{tabular}

Table 3. Disposal Scenario of G80.

\begin{tabular}{|l|l|}
\hline Material type & Disposal method \\
\hline Steel & Recycled $(90 \%)$ \\
\hline Copper & Recycled $(90 \%)$ \\
\hline Iron & Recycled $(90 \%)$ \\
\hline Resin & Incinerated (100\%) \\
\hline Fibre glass & Incinerated $(100 \%)$ \\
\hline Plastic & Incinerated (100\%) \\
\hline Concrete & Landfill $(100 \%)$ \\
\hline
\end{tabular}

The primary energy requirements and the emission factor for the second scenario for Kutch is shown in Fig. 5 . 


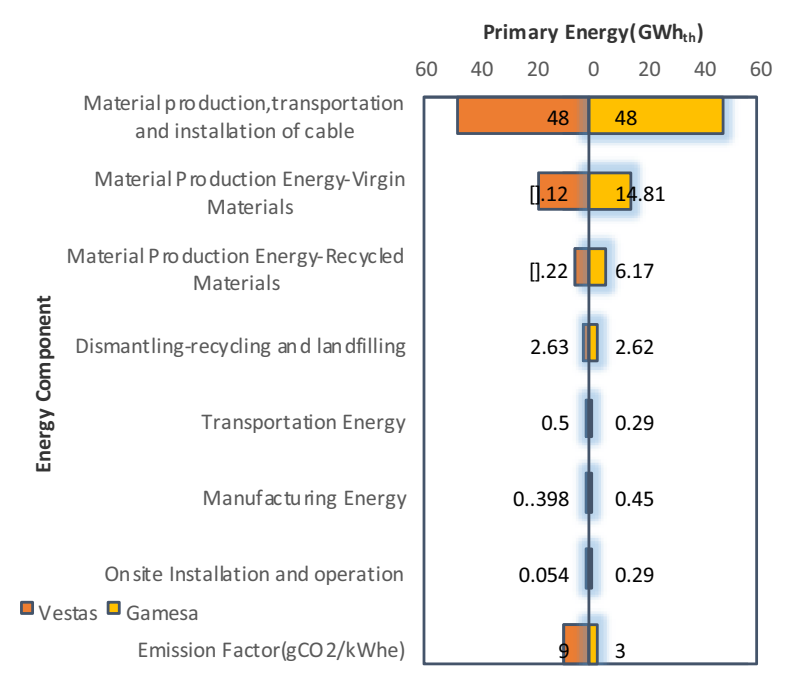

Fig. 5. Energy and emission comparison for Scenario2 for Kutch.

\section{Results and Discussion}

The EPBT and EF have been calculated for the four operating conditions of the wind farm- $100 \%$ landfill and partial recycling and landfilling scenarios for the two locations, Tuticorin and Kutch. The sensitivity of EPBT to the various factors are discussed in this section.

\subsection{Impact of Plant Load Factor}

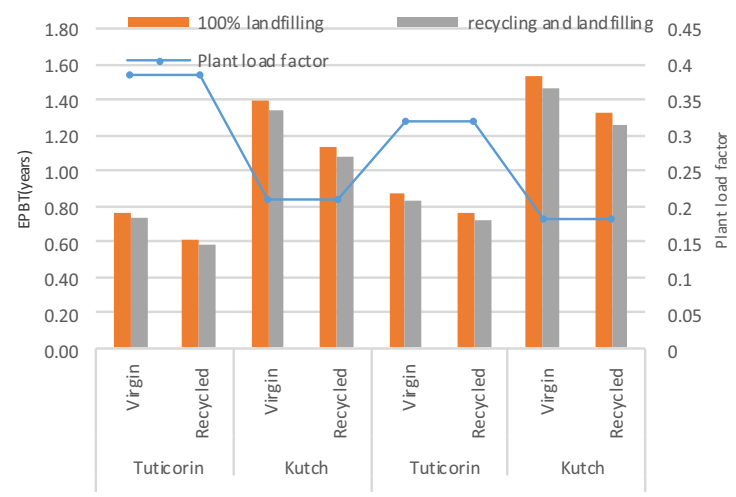

Fig. 6. Variation of EPBT and PLF.

Plant load factor is the ratio of available wind power potential to the rated power of the plant. It depends on the geographic location and the plant power characteristics Variation of EPBT and PLF for the two locations for the two disposal scenarios is shown graphically in Fig .6. It can be observed that, EPBT is less for a system with high PLF. The emission factor is found to be high for Kutch owing to the less PLF. The variation is shown in Fig. 7.

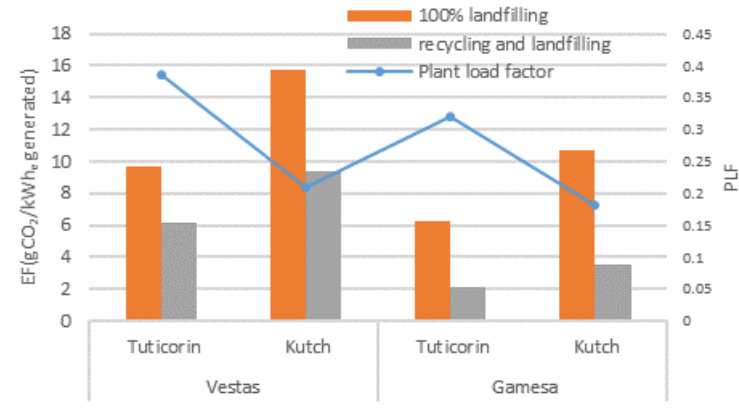

Fig. 7. Variation of EF and PLF.

\subsection{Impact of Recycling of materials for component manufacture}

Metals, which constitute more than $70 \%$ of the wind turbine and cable, can be recycled for secondary usage. It can be seen that there is a reduction of $19 \%$ in the total primary energy requirement for the Vestas turbine when calculated for the two locations for the 100\% landfill. Condition. Similar analysis shows a reduction of $13 \%$ for the Gamesa turbine. The values are $20 \%$ and $14 \%$ for the second disposal scenario.

\subsection{Impact of Transportation Energy}

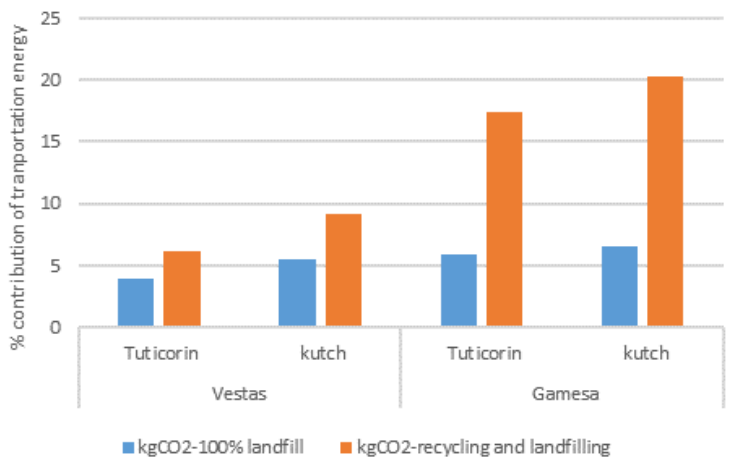

Fig. 8. Sensitivity to transportation energy.

Components of the wind farm are transported from different parts of the globe to the sites. It can be seen that they contribute less than $1 \%$ to the total primary energy requirement of the wind farm system. The Vestas turbine has more transportation component $(0.8 \%)$, than the Gamesa turbine $(0.4 \%)$ for both the disposal scenarios. The percentage contribution of transportation energy to the total carbon footprint of the system and the sensitivity to turbine type, location and disposal scenario is shown in Fig. 8. The total carbon footprint is more for the $100 \%$ landfilling option, thereby reducing the percentage contribution of transportation energy. Moreover, the carbon footprint is found to be high for Gamesa Turbine in comparison with the Vestas turbine, as the overall footprint is less. The overall results are tabulated in Table.4.This analysis helps in selection of 
turbine make and wind farm location, in terms of energy and environmental sustainability.

Table 4. Consolidated results for the two disposal scenarios for the two turbines.

\begin{tabular}{|c|c|c|c|c|c|c|c|}
\hline \multirow[t]{2}{*}{ Location } & \multirow[t]{2}{*}{ Model } & \multirow[t]{2}{*}{$\mathbf{V} / \mathbf{R}$} & \multicolumn{2}{|c|}{$\begin{array}{c}\text { Disposal } \\
\text { Scenario-1 }\end{array}$} & \multicolumn{2}{|c|}{$\begin{array}{c}\text { Disposal } \\
\text { Scenario-2 }\end{array}$} & \multirow[t]{2}{*}{ PLF } \\
\hline & & & EPBT & EF & EPBT & EF & \\
\hline \multirow{4}{*}{ Tuticorin } & \multirow[b]{2}{*}{ Vestas } & V & 0.8 & \multirow[b]{2}{*}{9.7} & 0.7 & \multirow[b]{2}{*}{6.2} & \multirow[b]{2}{*}{0.4} \\
\hline & & $\mathrm{R}$ & 0.6 & & 0.6 & & \\
\hline & \multirow{2}{*}{ Gamesa } & $\mathrm{V}$ & 0.9 & \multirow{2}{*}{6.2} & 0.9 & \multirow{2}{*}{2.1} & \multirow{2}{*}{0.3} \\
\hline & & $\mathrm{R}$ & 0.8 & & 0.7 & & \\
\hline \multirow{3}{*}{ Kutch } & \multirow{2}{*}{ Vestas } & $\mathrm{V}$ & 1.4 & \multirow{2}{*}{16} & 1.3 & \multirow{2}{*}{9.4} & \multirow{2}{*}{0.2} \\
\hline & & $\mathrm{R}$ & 1.1 & & 1.1 & & \\
\hline & Gamesa & $\mathrm{V}$ & 1.6 & 11 & 1.5 & 3.5 & 0.2 \\
\hline
\end{tabular}

\section{Conclusion}

This work proposes a comparison in terms of energy and carbon emission for large scale wind farms located in different locations in India. The energy generated is calculated using the wind speed data for the location and the wind turbine power curve. The impact of plant load factor, recycled materials and transportation energy on the sustainability of wind farms is analysed. Plant load factor has a negative relation with the energy pay back time and emission factor. The pay back time for the systems is in the range of 0.5-1.5 years. The cable transmission length has a major share of energy investment to the whole system. These are definitely site specific. Usage of recycled materials for manufacturing of components will decrease the material production energy of the system. Two disposal scenarios have been considered, out of which the partial recycling and landfilling option seems to be energy and environmental friendly. Transportation Energy doesn't play a major role in this study, as the other energy components are comparatively more. This factor is also turbine manufacture and location specific. This study can be a reference for energy and carbon footprint analysis of large grid connected wind systems in Indian conditions. The methodology can be made use for similar studies of different turbines at different locations of the country to examine their viability.

\section{References}

1. World wind energy association, 2018 report. Accessed: www.wwindea.org on 30-03-2018.

2. "Wind Power Development in India-An Overview",August-October 2017, Akshay Urja. Accessed: http://mnre.gov.in/file- manager/akshayurja/july-october- 2017/EN/Images/20-25.pdf on 3003-2018.
3. Elsam Engineering A/S, "Life Cycle Assessment of Offshore and Onshore Sited Wind Farms", Report by Vestas Wind Systems A/S of the Danish Elsam Engineering, 2004.

4. "Life cycle assessment of offshore and onshore sited wind turbines" Vestas Wind Systems A/S, Alsvij 21, 8900 Randus, Denmark (www.vestas.com),2005.

5. S.R. Carrascal, "Life Cycle Assessment of $1 \mathrm{Kwh}$ energy generated by Gamesa G114-2.0MW Onshore wind farm "Technology Department, Gamesa Corporation,2014.

6. K.R. Haapaala and P. Prempreeda "Comparative life cycle assessment of 2.0 MW wind turbines," International Journal of Sustainable Manufacturing, vol. 3(2), Jan. 2014, pp.170-185.

7. J. Yang and B. Chen "Life Cycle Assessment of Wind Power Generation System", In Handbook of Clean Energy Systems, J. Yan (Ed.), July 2015.

8. L. Xu, M. Pang, L. Zhang, W.R. Poganietz, S.D Marathe , "Life cycle assessment of onshore wind power systems in China" Resources, Conservation and Recycling, vol.132, May 2018, pp.361-368.

9. N. B Munir, Z Huque and R.R Kommalapati, "Impact of Different Parameters on Life Cycle Analysis, Embodied Energy and Environmental Emissions for Wind Turbine System”. Journal of Environmental Protection, vol.7,2016, pp.1005-1015.

10. ISO (1997) ISO International Standard, ISO/FDIS 14040, Environmental Management — Life Cycle Assessment - Principles and Framework.

11. ISO (1998) ISO International Standard, ISO 14041, Environmental Management — Life Cycle Assessment - Goal and Scope Definition and Inventory Analysis.

12. ISO (2000) ISO International Standard, ISO 14042, Environmental Management — Life Cycle Assessment - Life Cycle Impact Assessment.

13. CEA Annual Reports-Executive Summary-Feb 2018, http://www.cea.nic.in/reports/monthly/executivesum mary/2018/exe_summary-02.pdf; Accessed on: Feb 2018.

14. $\mathrm{CO}_{2}$ Baseline and Database for the Indian Power Sector Central Electricity Authority. Accessed: http://www.cea.nic.in/reports/others/thermal/tpece/c dm_CO2/user_guide_ver5.pdf;Accessed on: June 2017. 